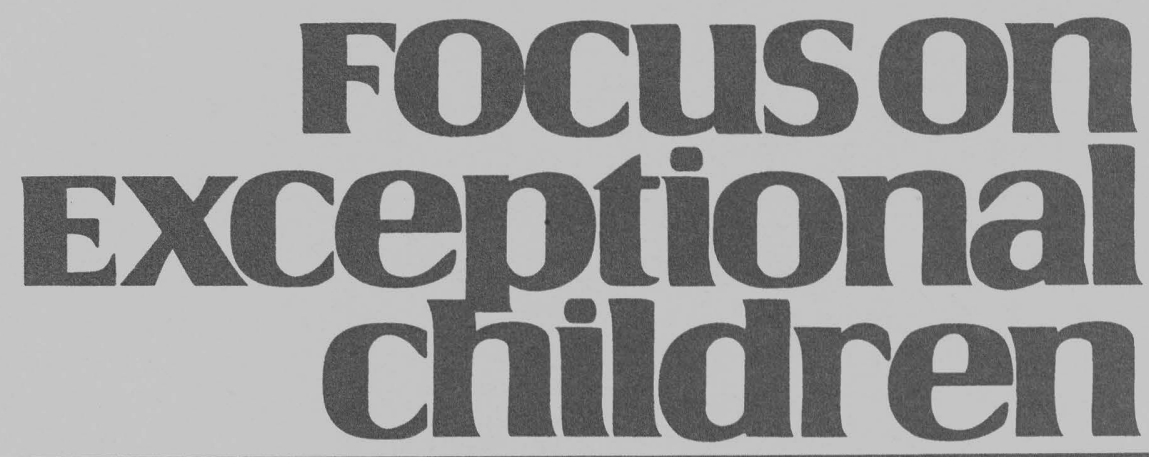

\title{
Applications of Online Instruction: An Overview for Teachers, Students With Mild Disabilities, and Their Parents
}

\author{
Sean J. Smith and Edward L. Meyen
}

With the emergence of the personal computer in the late 1970s came high expectations for the potential of technology to benefit education. It was anticipated that all students would benefit from this new technology, especially those with disabilities. It was expected that computers would enrich the education of the gifted and talented just as they would open new avenues to learning for students with disabilities (Cuban, 1986). This scenario was only partially achieved. Funds were insufficient to make computers readily accessible to students and even teachers. The publishing industry fell short in developing creative programs that were both effective and easily implemented. Teachers were ill prepared to integrate the use of this technology into their teaching, and higher education fell short in insuring that new teachers were prepared to use technology as an instructional tool (Office of Technology Assessment, 1995). There was, however, a response to exploit technology in the creation of assistive devices to enhance learning environments for students with disabilities. From an instructional perspective it was not until the evolvement of the World Wide Web (WWW) and the Internet did technology begin to significantly impact education. The educational benefits of technology are now beginning to be realized for all levels throughout the lifespan.

The role of the Internet in bringing about unprecedented growth in e-learning should not be minimized. The communication and distribution capacity of the WWW and the Internet have spawned a new form of pedagogy and given rise to renewed expectations of what technology can do for education and especially quality of life for persons with disabilities. The growth rate of online instruction for all levels of education and training in industry is difficult to comprehend-particularly when one realizes that the functional use of the Internet for instruction is less than ten years old. Streaming media was not a stable feature for instruction until 1997. Instructional Management Systems (IMS) such as WebTV and Black Board were not available in many educational institutions until 2000.

\footnotetext{
Sean J. Smith is Assistant Professor with the Department of Special Education at the University of Kansas. He specializes in Online Learning, Technology and Teacher Education, and Instructional and Assistive Technology. Edward L. Meyen is Professor in the Department of Special Education at the University of Kansas with specializations in curriculum and computers in Special Education.
} 
Today the lives of most people in the United States and other developed countries are touched in some way by technologies central to the Internet. For many, use of the Internet is a natural part of our daily routine; it is a tool for doing business, learning, and communications. That in itself contributes to the effectiveness of online instruction. For children who begin school already experienced in accessing the Internet and proficient in using computers, learning online should be as natural as learning from printed sources or from face-to-face instruction. Some might say that online instruction is already so prevalent that its growth will not be hampered by lack of research. Such a view is reinforced by the rapid advancement in new technologies and improvements in bandwidth. As improvements continue, the range of media that an be integrated into online instruction increases, leading to the use of instructional strategies that will far exceed what is now considered to be effective.

The purpose of this article is to illustrate how the technologies used in online instruction can be employed in the engagement of teachers and parents to impact the schoolrelated performance of students with disabilities. The focus is on instructional applications, and the intent is to give per-

\section{Focuson
Exceptional children}

ISSN 0015-511X FOCUS ON EXCEPTIONAL CHILDREN (USPS 203-360) is published monthly except June, July, and August as a service to teachers, special educators, curriculum specialists, administrators, and those concerned with the special education of exceptional children. This publication is annotated and indexed by the ERIC Clearinghouse on Handicapped and Gifted children for publication in the monthly Current Index to Journals in Education (CIJE) and the quarterly index, Exceptional Children Education Resources (ECER). The full text of Focus on Exceptional Children is also available in the electronic versions of the Education Index. It is also available in microfilm from Xerox University Microfilms, Ann Arbor, MI. Subscription rates: Individual, \$36 per year; institutions, \$48 per year. Copyright (C) 2003, Love Publishing Company. All rights reserved. Reproduction in whole or part without written permission is prohibited. Printed in the United States of America. Periodical postage is paid at Denver, Colorado. POSTMASTER: Send address changes to:

\section{Love Publishing Company \\ Executive and Editorial Office \\ P.O. Box 22353 \\ Denver, Colorado 80222 \\ Telephone (303) 221-7333}

Karen Harris

University of Maryland
Thomas Skrtic University of Kansas

James Shriner University of Illinois

Erica J. Lawrence Editor spective to current examples of online instruction and to illustrate how technology can be used to extend learning experiences for students with disabilities through the engagement of learners and stronger connections with teachers and parents.

The integration of the instructional environment with the home environment via online technologies, as illustrated in Figure 1, involves more than the mutual use of electronic communications. Teachers must not only utilize online instructional technologies, but also view parents and guardians as contributors to the instructional process. Additionally, the classroom and the home environments should be seen as opportunities for students to engage in activities that coordinate with or contribute to the instruction they receive face-to-face in the classroom. Online technologies offer the mechanism for bridging home and school with the added benefit of not being time or place bound (see Figure 2).

\section{ONLINE TECHNOLOGIES}

\section{Advantages}

For teachers, students, and parents, the WWW offers distinct learning opportunities. Over the past two decades, we have learned that instructional applications via software and multimedia tools can provide individualized experiences that are critical for many students who require accommodations (Wissick \& Garner, 2002; Edyburn, 2001). We know, for example, that instructional technology offers the following components to students with special needs: (a) extra practice to promote mastery skills; (b) development of writing abilities to convey understanding in content-based curriculum; (c) simulations and problem-solving opportunities to assist in mastering national, state, and local curriculum standards; and (d) overall access to the general education curriculum.

Today, the WWW extends multimedia and hypermedia lessons via a flexible, accessible, and ever-growing tool. That is, the Internet integrates these components as well as extends previous technology applications by combining many of these features in a cost-effective and accessible format that is often designed with considerations for all learn-

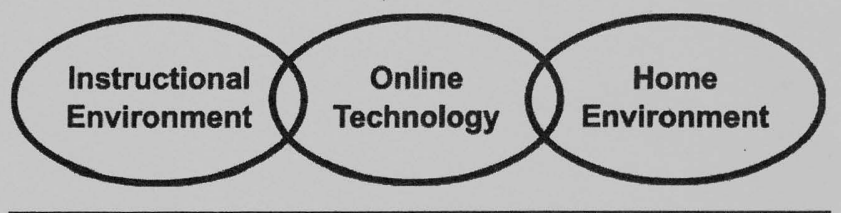




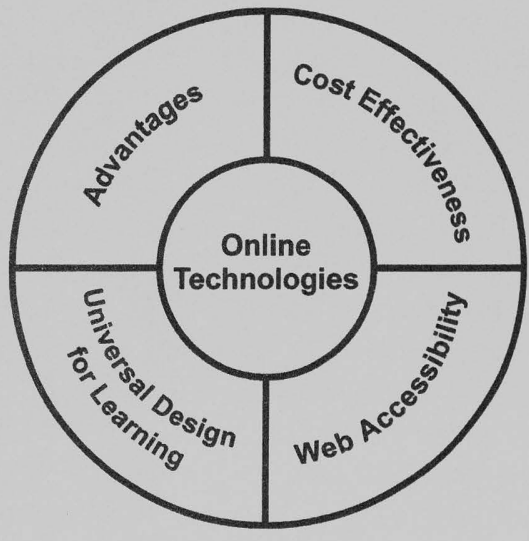

FIGURE 2

ers. Thus, the broad use and access to the Internet have created significant advantages for individuals with disabilities, their families, and related educational professionals with great potential still in store.

The investments that have been made over the past decade in terms of equipping schools, public facilities, and related environments for access to the Internet have been beneficial for all students. Unlike traditional assistive technology applications that are generally targeted for a select few students, the Internet is applicable to the general student population and thus represents a very cost-effective investment for students with disabilities. The growth of the Internet has coincided with public policy and education initiatives focused on the development of products that are accessible to the entire school population, including those with disabilities. As a result, accessibility guidelines have been created and continue to be edited as the Internet expands its application to teaching and learning. "Getting in on the ground floor," so to speak, means that future innovations and adaptations of the Internet will continue to consider accessibility issues.

The WWW, by its very nature, offers endless teaching and learning opportunities. Today, Web sites include text, hyperlinks, graphics, digital pictures, animations, audio and video clips, and other multimedia applications. With varied tools, it is easy to design, develop, and implement differentiated materials and learning opportunities to accommodate the needs of all students. As a result, a clear advantage of the WWW is its ability to serve as a tool in furthering what general and special education teachers can do to provide all students access to the general education classroom.

The merits of using online instruction as an option in teacher preparation, student learning, and school-home interaction go far beyond the obvious ones of flexibility in time and place and "just in time" delivery. While these advantages are important and made possible for the first time by the Internet, it is in the potential quality of online instruction from a pedagogical perspective that makes online instruction a sound option. Examples include:

1. The flexibility in time and place of online instruction dramatically increases access to pre $\mathrm{K}-12$ as well as higher education for students, teachers, and parents.

2. Students are able to review instruction in its original form as often as they wish.

3. Modeling examples can be provided in reliable form and reviewed repeatedly with no variance. For example, when researching how to teach phonemes in beginning reading programs, clear examples can be provided and the instructor will know that when the examples are reviewed they will be in the same form each time. Similar models can be created for other teaching situations.

4. Students are able to monitor the quality of their responses in online activities until they are confident enough to submit them to their teacher.

5. Feedback can be individualized to each student, meeting his or her specific instructional needs.

6. Tracking student progress can be designed as an integral element of online instruction, easily available to both teacher and parent.

7. Instructional management systems can be embedded in the course design, giving regular updates to all teachers working with a student, the child's parent, as well as the child.

8. Traditional geographic restrictions no longer limit information distribution among professionals and parents.

9. Communication among students can be enhanced and diversified offering various perspectives and frames of reference.

Despite all these advantages there remains the challenge of refining a pedagogy without the benefit of the traditional evolutionary process or developing new methodologies. That is, schools have historically taken a more cautious and conservative approach when altering instruction. The WWW and its ever-changing technology capability does not allow for laborious consideration. While caution is warranted, the WWW requires attention and cannot be ignored.

\section{Cost Effectiveness}

Since the early 1990 s, there has been a steady if not significant investment in classroom-based and schoolwide technologies. Increasingly, these technologies have included multimedia computers capable of interacting with and benefiting from an increasingly connected public school building. Combined student and teacher reports indicate a growth 
in the ratio of students to computers from 10:1 in $1995-1996$ to $5: 1$ in 1999-2000. It should also be noted that the ratio of students to multimedia computers appears to be even greater with changes from 24:1 during the 1995-1996 school year to an estimated 10.1:1 in 1999-2000. While the type of hardware and its ability to access appropriate information are critical, even at a 10.1:1 ratio, reports indicate that access to computers for group and individual instruction is improving each academic year in classrooms across the country. Meanwhile, the percentage of schools with Internet access rose from $35 \%$ in 1994 to $95 \%$ in 2000. Similarly, teachers reported individual classroom connectivity at $72 \%$ during the 1999-2000 school year (CEO Forum, 2001).

The growth in access to technology as well as the increase in connectivity for schools illustrate the investment in technology that has been made and is continuing to be made by state and local educational agencies. Unlike some traditional assistive technology software and hardware applications (e.g., augmentative communication devices), the access to the Internet offers teachers, parents, and students an interactive tool that can meet varied needs of diverse learners. That is, the WWW allows teachers to individualize instruction for specific student needs while using the same tool to facilitate group interaction, thereby offering all students access to the general curriculum. Quite simply, the Internet has multiple applications for multiple individuals without requiring a separate investment on the part of the school district as do some assistive technology devices. Similarly, state and local school budgets continue to make investments toward increasing and enhancing access to multimedia computers as well as increased connectivity. Investments do not necessarily mean extensive dollar costs. For example, many schools are increasing connectivity to the Internet for school buildings as well as individual classrooms through the use of wireless connections. Wireless broadband affords schools flexibility in cost and increased mobility for students and teachers.

\section{Web Accessibility}

Web content accessibility is a primary example of how the Internet has transformed technology in our schools today. With the expansion of the Internet, for example, state and federal agencies have developed and implemented Web Content Accessibility Guidelines (http://www.w3.org/WAI/ wcag-curric/), requiring that all Web-based resources developed or used by these entities are accessible to the entire public, including those with disabilities. For example, the state of Kansas developed and implemented the Web Content Accessibility Guidelines for the State of Kansas Implementation Guidance Version 1.0 (http://da.state.ks.us/itec/ WASGuidance102600.htm) in October of 2000. As a result, all branches of Kansas state government, including agencies, departments, divisions, bureaus, boards and commissions, and all other state organizations (e.g., universities) are required to develop and maintain Web sites that are as accessible as possible to all Web site visitors, regardless of disability. Web content guidelines for the state of Kansas require that Web sites (a) provide equivalent alternatives to auditory and visual content; (b) ensure that text and graphics are understandable when viewed without color; (c) ensure that tables have necessary markup to be transformed by accessible browsers and other user agents; (d) ensure that pages are accessible even when newer technologies are not supported or are turned off; (e) provide context and orientation information to help users understand complex pages or elements; and (f) use features that enable activation of page elements via a variety of input devices.

To assist developers in identifying accessibility issues within specific Web sites, products like Bobby (bobby. watchfire.com) have been created. Bobby assists developers in testing their Web pages for accessibility compliance. Pages can be tested using either the Web Content Accessibility Guidelines (WCAG) or the U.S. Federal Government's Section 508 Guidelines (http://www.section508. gov/).

Bobby has undergone four updates since its inception in 1996. Bobby's primary activity is to evaluate HTML pages, including pages that contain scripts or Dynamic HTML. Although Bobby does not have the technology available to process other formats (e.g., Flash, Java), it does check HTML tags and other components associated with the primary issues involving accessibility for individuals with disabilities. For example, if a teacher developed several HTML pages and wants to ensure they are accessible to his or her students and their parents, he or she may wish to run a Bobby scan. To do so, the teacher would enter the URL of the page he or she wants to test (at bobby.watchfire.com), select the guidelines to use, and click Submit. Bobby then provides a report noting areas of accessibility concerns. While Bobby is not the only software available to check HTML code (e.g., HTML Validator), it is the best for evaluating Web pages for accessibility to users with disabilities.

\section{Universal Design for Learning (UDL)}

Growth of the Internet over the past decade has coincided with an increased focus in education on applying principles of Universal Design for Learning (UDL) to classroom instruction, especially through the use of technology. UDL emphasizes the need for flexible and individualized content, assignments, assessments, and activities (CAST, 19981999). As described by Orkwis and McLane (1998), the universally designed curriculum is one that accommodates students' ability to see, hear, speak, move, read, write, organize, and recall. 
Today, components of UDL are being used in the development and design of electronic media and Web sites in an effort to increase access for people with diverse needs, abilities, and preferences. According to the Center for Applied Special Technology (CAST), universal design for learning has been made possible through the continued growth and development of cognitive neuroscience research tools, digital multimedia learning tools, and network technologies. UDL impacts teachers not only by acknowledging that no two students learn in the same way, but by increasing access for all learners, including those with disabilities, by equitably instructing and facilitating the curriculum. Thus, UDL provides teachers with a context in which to meet the needs of all learners and to ensure that students with a range of abilities can access, adapt, and be successful in the general education curriculum.

Edyburn (2001) and others have argued that technology has redesigned the tools available for teachers and, thus, fundamentally altered how teachers can teach. In support of this argument, consider the following examples concerning teachers and access to the Internet:

- Electronic databases and journals allow teachers to access research-based instructional methods, behavior management techniques, and other classroom interventions from almost anywhere at any time of the day or night.

- E-mail, chats, bulletin boards and other Internet-based communication tools offer constant access to teachers, parents, and students for questions and basically any information.

- Organizational, public agency and private Web sites offering myriad lesson plans have altered the way teachers can access effective lesson plans, accommodations, and other instructional ideas to meet the needs of students with disabilities.

- Instructional Web sites allow both general and special education teachers as well as parents to facilitate student instruction without requiring expertise in a particular content-based curriculum.

- Video, audio, and other media components have altered the way teachers can present material by providing simulations that offer context to the curriculum and thus an anchor or situated context for the learner.

In each of these cases, teachers, parents, or students have further access to materials, information, or applications that has the potential for improving how we teach and learn. In each situation, the Internet facilitates education but also complicates an already complex profession - that is, teaching students with disabilities. In order to benefit from what the Internet and WWW offer teachers, parents, and, most

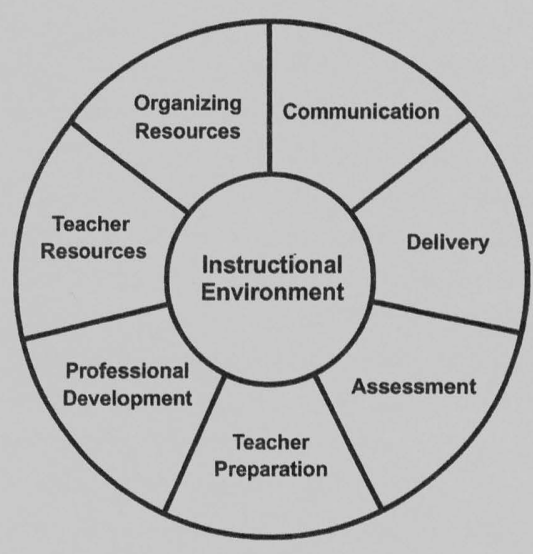

FIGURE 3

important, students with disabilities, it is important to understand how the Internet and WWW can apply to the instructional as well as the home environment.

\section{INSTRUCTIONAL ENVIRONMENT}

For teachers of students with mild disabilities, the Internet and the WWW present opportunities to access information, resources, instructional accommodations, and general lessons to use as they strive to meet the instructional needs of the student. Increasingly, the Internet and the WWW also offer current teachers and those interested in teaching in the future a medium to develop the skills necessary to teach students with disabilities. Next, we offer a sampling of how teachers are applying WWW-based applications and provide an overview of online certification programs being developed to meet teacher preparation needs.

\section{Tools for Accessing Resources}

Increasingly, general and special educators report using the WWW as a resource to supplement their lesson preparation and to access relevant information to be used in instruction (Tinker, 2001). In these cases, teachers are not necessarily employing the medium as an instructional tool for students, but they are gaining access to additional information that would enhance their ability to teach. For example, myriad Web sites offer lessons plans applicable to the needs of diverse learners. Many of these do not require Web use in the classroom (e.g., http://www.teach-nology.com/teachers/lesson_plans/special_ed/).

The Power of 2 (http://powerof2.org) is a Web site that features modules and instructional resources on effective collaboration among teachers, related professionals, and parents. For teachers seeking to create lesson plans that 
would further enhance collaborative opportunities, the Power of 2 offers a list of lessons organized by content and grade level (http://www.powerof2.org/ resources/). Thus, a middle-school science teacher could quickly access a modified unit on the nervous system for seventh graders. If the teacher wishes to use the web, Power of 2's "Resource Section" also includes a series of links targeted for similar collaborative purposes.

For the teacher looking to integrate local and state standards while also meeting the needs of students with disabilities, MCREL (http://www.mcrel.org) and other reference sites offer downloadable lesson plans. Organized under the content area (e.g., science), the "Lesson Plan Library" offers hundreds of lesson plans, linked to state and local standards, that teachers can apply into their classroom teaching. Other sites where teachers can access lesson plans and activities include Eisenhower National Clearinghouse (http://www. enc.org/), Ask ERIC (http://www.askeric.org/Virtual/Lessons/), DiscoverySchool.com (http://school.discovery.com/lesson plans/), Teachernet (http://teachers.net/lessons/), the Lesson Plans Page (http:// www.lessonplanspage.com/), Teacher's Corner (http://www.teacherscorner.net), and 4 Teachers (http://www. 4teachers.com).

\section{Tools for Organizing Resources}

Faced with such an abundance of information, the challenge for many teachers involves finding resources in an efficient manner, reviewing and identifying instructionally appropriate resources to enhance current curriculum, and constructing an effective delivery format to ensure appropriate integration and subsequent learning (Higgins, Boone, \& Williams, 2000).

One tool teachers, parents, and students with disabilities can use is the High Plains Regional Technology Education Consortium's (HPR*TEC) TrackStar (http://trackstar.hprtec. org/). This online resource helps teachers and students organize and annotate Web sites (more specifically, the addresses or URLs to the Web sites) into lessons, presentations, assignments, or instructional resources. Similar to bookmarks (Netscape) or favorites (Internet Explorer), TrackStar allows users to organize favorite Web sites into Tracks under a specific topic and make them accessible to anyone with Internet access. TrackStar addresses primary issues for many teachers who are attempting to incorporate the Web into their teaching: how to locate instructionally appropriate Web-based resources; how to organize what you find; and how to make selected resources available to all students without investing a significant amount of time and resources.

TrackStar not only provides students with the means to organize and annotate their selected Web sites, but also makes available to them a rich library of Tracks created by other educators and students. This resource provides teachers with just-in-time and content-specific resources for use in their classroom. Similarly, TrackStar represents the essence of technology integration. By providing a simple, easy way to organize and annotate educationally appropriate Web sites, teachers are able to:

- Control access to specific Web sites;

- Provide educationally appropriate and safe Web resources for all students;

- Control scope and sequence of instruction;

- Address specific needs outlined in a student's IEP;

- Create a renewable educational resource;

- Share their Tracks with other educators;

- Acquire just-in-time resources and lessons created for special education classrooms.

Tracks are created by teachers, parents, or students and are stored on servers at HPR*TEC. All of the Tracks, approximately 70,000 , are organized and cataloged by grade level. Users can select from Tracks created for early childhood, primary grades $(\mathrm{K}-2)$, intermediate grades (3-4), middle school (5-9), high school (9-12), college/adult or all grades. Likewise, users can select Tracks organized by keyword (e.g., special education), by author, or by themes and standards. For users interested in the most popular Tracks, there is the Month's Track-A-Day, a list of all "Top Tracks," and Tracks by subject/category. For the user who is uncertain of how to begin locating a Track, TrackStar has a "How to Find a Track" tutorial.

Each Track provides a user with a list of Web-based resources offering easy access to the content. For example, if a teacher is searching for resources concerning word recognition, keyword search using this term brings up 20 Tracks created by other educators or students. Each Track offers a title, an annotated summary for the entire Track, and a reference (and often an e-mail address) to the author. One teacher, for example, created a Track entitled Using Different Strategies to Teach Word Recognition. According to her summary, she located Web-based resources concerning word recognition that would help students who had difficulty decoding unknown words. She included five word recognition Web sites and provided a summary for each. Her second Web site provides activities which will help students to learn the most basic words. It also includes online activities and printable activities as well as resources for assessment, a sight words list, and articles. Her learning objective for this site is to develop a reading vocabulary utilizing sight words, phonetic and structural analysis, and context. When users select this site, they are linked to Thinkquest (http://www.thinkquest.org/) and its list of questions and possible activities for students. 


\section{Tools for Communication}

There are several advantages and few disadvantages of Web-based communication between teacher and student, student and student, and teacher and parent. Asynchronous communication methods (e.g., e-mail, class listservs, bulletin boards) are often more convenient than immediate interaction because everyone can use these tools whenever he or she has time. Synchronous communication methods (e.g., chats), on the other hand, offer immediate interaction and can be used for teachers to interact and share perspectives, students to gather as a group cooperatively, or parents to share concerns and seek support related to their child's needs and possibly specific to his or her disability (e.g., chat room on Down syndrome).

For teachers, the Internet is a medium through which they can share information about their classroom, related assignments, weekly quizzes, and general classroom news. For example, online calendars offer parents and students immediate access to the daily lesson, related assignments, and information on upcoming quizzes or tests. If a child were absent or happened to forget his or her assignment at school, the student's parent or guardian can easily access the calendar and learn about the daily activity and download the assignment sheet for that day. Increasingly, teachers are offering resources to assist the student in completing assignments. This might include a link to a strategy page (http:// coe.jmu.edu/learningtoolbox) or study strategies (http:// www.iss.stthomas.edu/studyguides), or assistance with completing homework assignments. Helpful sites include: Study-WEB (http://www.studyweb.com), BJ Pinchbeck Homework Helper (http://school.discovery.com/homework help/bjpinchbeck/), and The Homework Spot (http:// www.homework spot.com/).

A critical concern for parents is grades and what they can do to assist their son or daughter. Sending weekly or periodic messages via e-mail is an easy strategy to keep parents with home Internet access informed of student progress. Some schools are investing in web-based software that offers controlled password-protected Web sites. For example, states such as Kansas and large school districts such as Fairfax County Public Schools, a Virginia school district just west of Washington, DC, have invested in Blackboard (http:// www.blackboard.com), a total "e-Education Infrastructure" for schools to deliver instruction as well as organize and disseminate information in a safe and secure environment. Through BlackBoard, teachers can post grades that are accessible only to parents with the appropriate User ID and corresponding password.

\section{Delivery of Learning Materials}

Possibly one of the greatest advantages of the Internet for teachers is the delivery of learning materials, primarily ones that offer self-instruction, via the Web. This may include text material equivalent to textbooks and other readings. In the area of reading, for example, online and electronic resources have increasingly become available for readers of all ages and learning needs. Considering the emphasis in reading for all children, it is not surprising that the number of Web sites available for literacy instruction is growing expotentially. The potential for teachers as well as parents to find and use electronic text-based materials for literacy instruction continues to evolve and increase in accessibility.

Why use text materials that are available via the Internet? For starters, the sites can be of high interest to students by further motivating them with, for example, authentic situations. Internet text materials are also accessible and available to all. The interactivity of sites offers varied media (e.g, graphics, audio, video) to provide a context for learners as they learn to read for meaning, comprehension, and application. That is, the use of graphics and alternative media supports content meaning and the expression of the ideas written on the page through pictures, drawings, graphics, and other visual illustrations. In this way, the Web-based multimedia offer the learner context to the reading and a new tool to approach textual material (Cognition and Technology Group at Vanderbilt, 1990).

Multimedia applications for reading are not limited to the Internet (e.g., Scholastic's Read 180; see http://teacher. scholastic.com/read180/), but the use of the Internet has expanded opportunities for teaching and learning in the special education classroom, specifically for students with mild disabilities. For example, Literacy Access Online (http:// www.literacyaccessonline.com) was developed to assist students in the reading process. The site centers on stories that are developed by Literacy Access, written by visitors to the site, or available via other Web-based resources. For each story, prereading activities help the reader relate to the story, review upcoming vocabulary, and predict story events through pictures and other media. As the child reads the story, he or she can select hyperlinked vocabulary that offers audio pronunciation assistance to help with vocabulary building. Comprehension questions organized throughout the story encourage the reader to think about the passage while graphics offer a contextual illustration for the student. Postreading activities include a series of activities that further promote comprehension as well as teach phonic skills in relation to the specific story. Likewise, the site offers reading strategies to improve students' reading comprehension skills. For parents or teachers, a list of motivation strategies offers suggestions for how to encourage, monitor, and reward children while they read. Finally, there are links to internal and external resources to help facilitate, plan, and guide reading sessions.

Another tool available to teachers and parents is The Intersect Digital Library (http://intersect.uoregon.edu/). 
Developed to address the challenges students with disabilities face in comprehending text materials in content-based curriculum, Intersect features a library of digital books (e.g., On the Run by Willa Holmes), a Teacher's Center featuring lesson plans and activities associated with the digital books, and guidelines for creating digital books. By placing the book online, Intersect has developed a series of resources to extend the student's ability to comprehend the text (e.g., gallery of characters). The intent is to offer an interactive reading experience to support student comprehension, extend the application of reading strategies, and provide background information and, thus, a context for the reader. The outcome improves content area achievement for learners with reading disabilities and thereby helps the student meet state standards associated with the curriculum.

The list of online resources to assist in the reading process for students with disabilities is extensive. Popular sites for learning more about reading and the strategies to improve reading skill, include, among others, Reading Rockets (http://www.readingrockets.org), ReadyWeb (http:// readyweb.crc.uiuc.edu/), and LDOnline In-Depth—Reading (http://www.ldonline.org/ld_indepth/reading/reading.html. Likewise, Web searches yield countless Web-based references to the reading process, reading readiness programs, and reports describing best practice for all students, especially those with reading challenges.

\section{Assessment-Student Portfolios}

An important component of teaching is the ability to measure student understanding and, if necessary, to alter instruction accordingly. In recent years, teachers have adopted alternative forms of assessment to measure student comprehension. For example, student portfolios have gained increased attention as new instructional approaches and performance-based standards emphasize the student's role in constructing understanding and the teacher's role in promoting understanding. A portfolio may be a folder containing a student's best pieces and the student's own evaluation of the strengths and weaknesses of the pieces. It may also contain one or more works in progress that illustrate the creation of a product, such as an essay evolving through various stages of conception, drafting, and revision. Thus, portfolios can function to illustrate the range of assignments, goals, and audiences for which a student produced written material as well as serve as a record of the activities undertaken over time in developing the written product.

For students with a disability, portfolios offer multiple applications. For instance, portfolios offer a place to collect and organize work that can then be viewed sequentially in its development, recording student progress as well as various drafts of efforts in accomplishing a task. Portfolios capitalize on students' natural tendency to save work and are particularly effective in enabling students to take a second look at their work and think about how they could improve future work (e.g., further edits in a writing task). Today, electronic or digital portfolios are increasingly being used as the medium to collect student work and, thus, illustrate student progress. Like traditional paper and folder portfolios, electronic portfolios are selective and purposeful collections of student work, but the work is made available via the WWW.

Why use electronic portfolios? Unlike paper- and folderbased portfolios, electronic or digital portfolios offer students with disabilities the chance to become engaged learners. There is little reason for students to develop ownership of standardized test scores filed away in the office. Electronic portfolios, however, help students set goals for learning, review their goals periodically, and assume responsibility for their own learning. More important, having a chance to display their work to anyone via the WWW is much more motivating for students than producing only for the teacher. Being available for the world to see, electronic portfolios often encourage students to engage in periodic self-reflection, an important learning component that is often missed by individuals with disabilities. Likewise, electronic portfolios allow for ongoing and interactive evaluation of the efficiency of learning goals, the effectiveness of learning strategies, and the clarity of knowledge presentation. Altogether, this leads to a system of feedback that can simultaneously evaluate several processes in the educational cycle. Finally, being available online, feedback can also be exchanged between teacher and student as well as teacher and parent or related professionals.

Increasingly, electronic portfolios are featuring multimedia products. The very nature of the electronic portfolio lends itself to an interactive illustration of the student's work. Although writings may be collected easily in a notebook or folder, samples of oral readings, graphics, interactive presentations (e.g., PowerPoint presentations), animation, and video illustrations are more suitable for electronic portfolios available via the WWW.

Among the variety of Web sites created especially to provide information about electronic portfolios as well as to aid teachers and students in creating electronic portfolios are the Electric Teacher's Online Portfolios (http://www.electric teacher.com/onlineportfolio/) and The Electronic Portfolio Development Process (http://transition.alaska.edu/www/ portfolios/howto/model.html).

\section{Teacher Preparation}

There might be no precedent in the history of higher education and professional development that parallels the emergence of a new form of teaching (i.e., pedagogy) as is occurring with online instruction (Walker \& White, 2002; Zirkle, 
2002). Changes in pedagogy have tended to be evolutionary. The seminar, didactic forms of instruction, mentoring, practica, and internships have emerged gradually over time. As with all other functions of the Internet and the WWW, however, we have seen unprecedented rapid growth in the use of online instruction (Meyen et. al, 2002).

While online instruction might not replace face-to-face instruction, it is an important option that can enhance efforts in personnel preparation and help meet the personnel needs of the special education field. The advantages of online instruction as an option in personnel preparation and professional development go far beyond the obvious ones of flexibility in time and place and just-in-time delivery. While these benefits are important and made possible for the first time by the Internet, it is the potential quality of online instruction from a pedagogical perspective that makes it a sound instructional option.

Because technology makes this new pedagogy possible, schools of education are faced with having to build and refine a pedagogy without the benefit of the traditional evolutionary process. Most colleges and universities have taken a very cautious approach and are often reluctant to invest in developing the pedagogy of online instruction (Blackhurst, Lahm, \& Hales, 1998). At the same time that many comprehensive universities have taken this conservative approach, for-profit institutions in the form of virtual universities have emerged. For example, The University of Phoenix has 37 campuses and has provided degrees and certification classes to over 371,000 working professionals (www.uophx.edu). Community colleges have been responsive to the opportunities offered by online instruction as have many regional universities that have strong commitments to outreach (e.g., www.kckcc.cc.ks.us/online). Even industry has entered the online instructional field. This is reflected in the announcement by AT\&T that they are initiating the AT\&T Network Virtual Academy focusing on teacher education (www.att. com/learningnetwork/virtualacademy). The availability of personnel with the knowledge and skills to influence the quality of online instruction is essential to the employment of online instruction in special education personnel preparation programs (Blackhurst, Lahm, \& Hales, 1998).

The use of distance education technology is not new to the field of special education teacher preparation (Collins, Schuster, Ludlow, \& Duff, 2002; Spooner, Agran, Spooner, Kiefer-O'Donnell, 2000). Efforts to address shortages, geographical limitations, and the training of unqualified teachers holding positions in special education have served as the impetus for the development and implementation of such programs. Distance education has been seen as advantageous because of its potential to reach a large number of students across a broad geographical region. This is of particular importance in specific areas of disabilities (e.g., low incidence), where often a minimal number of institutions offer coursework to a limited number of students scattered across districts and regions. For example, in the state of Kansas the only institution to offer teacher preparation in deafness as well as severe and profound intellectual and physical disabilities is the University of Kansas. Located in the extreme eastern part of the state, the university is expected to serve district certification needs across a wide geographical distance with some districts being as far as an eight-hour automobile ride away from the Lawrence campus. Across the country, states have increasingly used distance education technologies to deliver coursework, especially for low incidence disabilities where positions are often difficult to fill and most programs have limited number of interested students. Over the past decade, teacher preparation programs that have featured distance education efforts have reported the necessary components, shared evaluation data, and offered direction for future development of distance education personnel preparation efforts (Meyen, Aust, Bui, \& Isaacson, 2002).

In recent years, online coursework has emerged as a widely used distance education technology due to its flexibility, accessibility, and the relatively low delivery costs associated with developing, delivering, and accessing the content. With this growth, an understanding of the potentials of online instruction has evolved. For example, Blackhurst, Lahm, and Hales (1998) offer an understanding of the technological components necessary to deliver courses entirely over the Internet. Collins and her colleagues (2002) continue this discussion, addressing three aspects of planning and delivery of online content: (a) online support services, (b) technology assistance, and (c) course content. In short, they offer recommendations for higher education administrators as well as teacher preparation instructors on issues related to planning and delivering online coursework in special education.

One example of a special education certification program that is conducted almost entirely online can be found at the University of Georgia. Special Education Training on the Web (SETWEB; http://www.coe.uga.edu/setweb/) is an alternative certification program that was originally designed for individuals who already had a teaching certificate in one area and were teaching special education on a provisional basis. The current program is called SETWEB: Business-toTeaching. The SETWEB Business-to-Teaching program of study typically includes the following:

- Six Web-based courses

- Eight teleconferences (provided at no cost to the student)

- One three-day SETWEB Academy

- One two-day Beginning Teacher Academy (face-to-face)

- Two onsite practicum courses

- One four-day summer institute 
Thus, a student receives certification to teach students with disabilities without ever setting foot on the University of Georgia campus. More important, the various onsite activities foster collaboration among school district personnel to ensure that district-based participants and teachers gain a better understanding of effective instruction for students with special needs.

In Virginia, the integration of distance education technologies, including videoconferencing, has become an integral part of a collaborative preparation program between four universities to prepare teachers of students with severe disabilities (SD). The Virginia Consortium for Teacher Preparation in Severe Disabilities (http://kihd.gmu.edu/ sdconsortium/) includes Virginia Commonwealth University, Lynchburg College, the University of Virginia, and George Mason University. The consortium utilizes videoconferencing equipment to establish real-time, interactive, multipoint conference instruction supported by a Blackboard online course delivery system, which provides $24 / 7$ asynchronous access to other students, professors, and course materials. A video streaming server provides access to individual students more than two hours away from any of the participating universities and acts as an archive to the course.

Another example of the exponential growth of online education is The Online Academy at the University of Kansas (http://www.onlineacademy.org/), a project funded by the Office of Special Education Programs (OSEP), which has produced 22 online modules for teacher education that were adopted by over 160 universities (Meyen, 2002). $\dagger$ Nearly 710,000 students in 1998 were enrolled in at least one online course-a figure that was predicted to reach 2.2 million by 2002 (Meister, 2000).

Today, some online teacher preparation programs are considering the use of Reusable Learning Objects (RLO). The concept of RLO as applied to online learning is that objects created for a particular course (e.g., Introduction to Special Education) can be used across courses and universities to expand instruction. For example, within many current online efforts faculty members work individually or with limited partners to create an effective online learning experience for their students. They either create or access certain online resources usually from a limited network of resources. In the RLO model, a faculty member can access a variety of online learning objects that are context free and thus usable across curricula and for a variety of purposes. The potential is that a faculty member could access a cluster of resources from an online "library" where curricula would be categorized under information, audio, video, assessments, terms, or activities. The advantage of the RLO model is that faculty members can share resources developed by a variety of users. More important, resources can exceed what an individual faculty member might be able to create with limited time and resources, thus expanding the efficacy of the online develop process.

\section{Professional Development}

Online professional development is becoming big business, and the continuing emphasis provides a unique opportunity to shift the culture of professional development away from "one-shot dog and pony shows" to delivery models that promise more lasting effects (Joyce \& Showers, 2002). To accomplish such a shift, professional development strategies must extend over time, respond to the needs and concerns of teachers, and impact student learning. According to Joyce and Showers (2002), instructional change will occur only when professional development experiences: (a) offer demonstration of the new strategy or instructional tool; (b) offer opportunities for structured practice; (c) are ongoing and accessible to the user when necessary; (d) offer critical feedback to the user to ensure comprehension; and (e) are flexible to meet the varied needs of the teachers involved. Fortunately, the challenges imposed by time constraints and growing expectations of teachers to understand and implement new techniques, educational standards, and reform efforts are coupled with a growing use of, access to, and understanding of the Internet and WWW. As Fine (1994) noted, "Technologies can support and broaden professional learning communities and help teachers make better use of their time. Through a range of technologies, e.g. the Internet and video-audio conferencing, teachers can access both instructional resources and collegial networks" (pp. 5-6). In fact, one of the most beneficial components of technologyassisted professional development is the ability of teachers to participate in direct instructional activities when it is convenient to them. Similarly, effective professional development offers an ongoing 24/7 feature that allows users to access when, what, and where they desire based on their schedule and not that of a structured, preplanned training day.

For special educators, professional development materials available via the WWW are increasingly accessible, interactive, and instilled with the principles of what makes professional development effective. More important, many of these WWW-based learning modules are targeted at enhancing what general and special education teachers can do to provide further access to the general education curriculum. For example, MathVIDS (Video Instructional Development Source; http://coe.jmu.edu/mathvidsr/) offers video clips of elementary-grade classrooms, where teachers are illustrating how to effectively teach math concepts and skills to students who have difficulty learning mathematics. These video clips can be viewed with or without elaborative audio and text, and the elaborations highlight the salient features of each strategy. 
Guided practice via the WWW can be created to meet the individual as well as the group needs of the professional development cohort. The Power of 2 (http://powerof2.org), for instance, introduced concepts associated with effective collaboration, and, through various modules (http://www. powerof2.org/modules/), participants can practice individually as well as with their collaborative team members to develop the necessary collaborative skills (e.g., ability to listen). MathVIDS, the Power of 2, and similar WWW-based learning tools offer continuous access and training for users striving to implement the instructional idea into their individual classroom.

To ensure use of educational innovations, Joyce and Showers (2002) also speak of the need for critical feedback from the instructor or facilitator to teacher participants. Understanding what participants did wrong, suggestions for solutions, and feedback on the next step to take are all critical elements while participants explore the innovation implementation in the classroom. The Staff Development Module (http://www.elearndesign.org/resources.html) developed by the eLearning Design Lab (http://www.elearn design.org/) offers feedback through various assessment features. For example, the module on developing standardsbased IEPs is organized into five distinct lessons, each concluding with a series of multiple-choice and short-answer questions. In addition, at the end of the module, a practice activity is available to evaluate comprehension and application of the content. All three assessment tools feature immediate feedback options and redirection back to components of the module for further review on the part of the teacher.

Finally, professional development standards call for flexibility in content (i.e., specific for the individual while also serving the needs of the group), accessibility, and consideration of the professional development needs of the individuals as well as the group. The nature of the WWW ensures a flexible, 24/7 access to the training, thus imposing no limitation on teachers to revisit the site when necessary. But it is not simply access that makes the WWW a flexible medium and, therefore, an extremely flexible medium for professional development. It is also the design of the content to be accessed from a number of entry points based on the needs of the learner. Simply put, if learners understand the concept, they have the ability to bypass the content and progress with their training.

The Assistive Technology Training Project (ATTO) (http://atto.buffalo.edu/) is one of several examples of this kind of flexibility currently available via the WWW. The ATTO provides information on assistive technology applications that help students with disabilities learn in general and special education classrooms. The lessons are organized in such a way that learners can progress sequentially through course material to gain experience in AT. Similarly, users can look upon ATTO's home page as a menu of à la carte items giving users the ability to choose the training they require on the issues in which they have weaknesses. So, if they desire to know more about Using the Computer for Reading (http://atto.buffalo.edu/registered/ATBasics/ Curriculum/Reading/index.php) they can do so just as easily as they can access online tutorials of reading and writing software (e.g., Co:Writer 4000; http://atto. buffalo.edu/registered/Tutorials/cowriter/index.php). The challenge for the teacher and the professional development facilitator is to focus on the benefits of the online medium while instilling the professional development principles the medium can support.

\section{HOME ENVIRONMENT}

\section{Parent Resources-Information}

Parents may have gained the most from the growth of the Internet. In the past, parents who wished to expand their understanding of their children with disabilities and the special education process were often limited to reading a textbook or refereed journals on the topic. Some may have been fortunate enough to live near a university that offered a traditional teacher preparation course in special education. Today, however, the situation has changed. Thanks to the Internet, myriad educational opportunities exist. Not only is the Internet filled with sites exclusively dedicated to individuals with disabilities and special education, but also many universities with special education programs (e.g., http://www.onlineacademy.org) now offer courses online to an increasing number of students.

Through the Internet, many parents have become further empowered in advocating for their son or daughter. With information available at the click of the mouse, parents are educating themselves and others about their child's disability, available services, and overall expectations for their child. The result is a connected parent who has access to a cyber support group that can educate, advocate, and basically empower the parent to seek what is best for his or her son or daughter. For example, take a parent of a child with Cri Du Chat or the more appropriate term, $5 p$ syndrome. This is a rare genetic disorder that is not understood by many, but, through the Internet, a new parent can access a Cri Du Chat Support Group (http://www. cridchat.u-net.com/) and learn from other parents firsthand. More important, these parents have direct access, not limited by geographical constraints, to emotional support from parents who are experiencing the same challenges.

Information about a given disability and what to do for their child is often critical for parents. Through the Internet parents can gain answers to questions about health issues, 


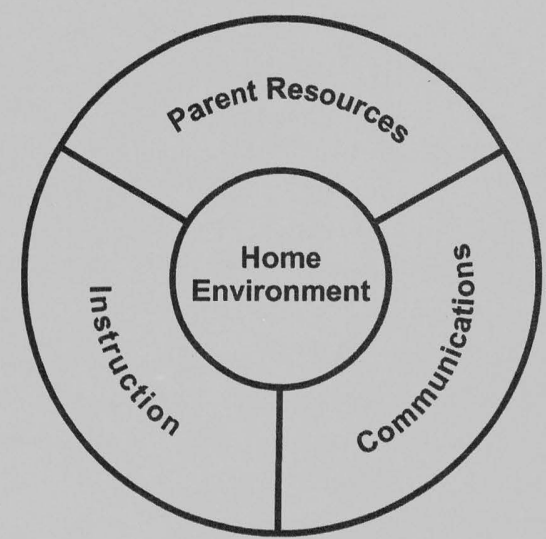

FIGURE 4

educational programs, and community-based resources. Traditionally, if parents had questions concerning health they waited to see their local pediatrician, hoping the doctor had experience with, for instance, a child with Down syndrome. If the local health professionals were not informed, parents were out of luck. Today, Web sites such as Down syndromeHealth Issues (http://www.ds-health.com/) offer news and medical information concerning Down syndrome. Like many similar web resources, the site was created and is maintained by a parent of a child with Down syndrome who happens also to be a pediatrician. LDOnline (http://www. ldonline.org) is another example of a Web site created by a parent of a child with a learning disability for parents, educators, and students to learn, find, and exchange ideas concerning learning disabilities.

Similarly, professional organizations and their related Web sites offer information and general disability-based resources for parents. The Council for Exceptional Children's Division for Learning Disabilities recently developed TeachingLD (http://www.teachingld.org/) for the purpose of providing trustworthy and up-to-date resources about teaching students with learning disabilities. Although the title implies that the site is for teachers, the resources are presented in language that would be comfortable for the layperson. Increasingly, Web sites also offer "Ask the Expert" sections where, via live chats or e-mail submissions, parents are able to interact with experts in a specific field of disability.

\section{Communications}

The growth of the Internet and the advancements in technology appear to only increase the ways teachers, parents, and students can communicate. The ever-expanding list includes e-mail, listservs, bulletin boards, chat rooms, audio teleconferencing, and video teleconferencing. For parents and teachers these mediums can add to existing communication in many ways. For example, teachers may use e-mail to send to the home periodic updates on grades, assignments, strategies to use at home, and classroom news. Bulletin Boards may be used to post assignments and facilitate ongoing discussions on particular classroom assignments or initiatives. Chat rooms may be used to offer synchronous interaction without complicating schedules by requiring physical presence.

Teacher-parent communication is becoming increasingly easier via the use of the Internet. Web sites such as Scholastic's Teacher Toolkit (http://teacher.scholastic.com/teacher toolkit/) and School Notes (http://www.schoolnotes.com http://www. schoolnotes.com) offer teachers tools to communicate with their students as well as their students' parents. School Notes, a free service, is an excellent example of a resource offering everything a teacher might need to communicate with students and parents. School Notes allows teachers to control their own Web site and use their imagination to post what they want. Students and parents can quickly e-mail the teacher with specific questions they have about the posted information. Posting can include relevant homework assignments, weekly grades, announcements, class attendance, classroom activities, upcoming events, and related information pertinent to the classroom. Parents can use the site to inform teachers of upcoming doctor appointments or family vacations and request that missed assignments be posted online.

With easily accessible information and open lines of communication between the teacher and the parent, students often become more responsible for their own education. For example, as long as the information on the Web site is current, a forgetful or unorganized student can access the assignment upon returning home. By checking the Web site, parents can review the assignment, offer assistance if applicable, as well as remind their child of relevant materials he or she needs to bring to class the next day (e.g., assignments, textbooks). Students who miss class can view the site, understand what instruction was missed, and realize what they need to prepare for the next day's instruction, thus eliminating the question "What did we do in class yesterday?"

Web sites such as School Notes and others also provide areas to create review questions for upcoming tests. Teachers can offer tips on study skills, introduce or link to learning strategies, and then encourage students to work with their parents and vice versa. Parents can also participate by reviewing class material with their son or daughter (e.g., via flash cards) to prepare them for an upcoming test.

Finally, School Notes and similar sites include options such as "Favorite Links," which point students (and their parents) to more information for an assignment. If a parent 
or student finds a resource of interest, it can be posted there as well.

\section{Instruction}

Ultimately, parents seek to provide the best support, advocacy, and education for their child. To do so, parents need to be educated about their child's disability, specific instructional needs, health issues, and other information pertinent to parents in general as well as to parents with a child with a specific disability. As mentioned earlier, part of this information may be gained from interaction with other parents via face-to-face and online interaction. For parents of children with low-incidence (i.e., less prevalent) disabilities identifying parents who are experiencing similar challenges can be a critical first step in understanding what is necessary for their son or daughter. Thus, resources such as the Down Syndrome Support Group (http://www.nas.com/downsyn/ parent.html), The Father's Network (http://www.fathersnet work.org/), and the Family Village (http://www.familyvil lage.wisc.edu) are the lifeline some parents need as they grapple with understanding their child's disability and possible ramifications in his or her overall development.

Increasingly, Web sites are being created specifically for parents of children with disabilities to instruct them about their child's disability, special education, community-based resources, and other relevant information to assist in making life-long decisions. One of the best of these sites is LDOnline (www.ldonline.org), created initially by a parent of a child with a learning disability. Although LDOnline is one of the premier WWW resources on learning disabilities, it also offers information about technology, special education law, transition issues, and behavior management that applies beyond a specific learning disability. Therefore, the site offers instruction for parents, teachers, and students concerning special education and disabilities in general. Similarly, Web sites such as Special Child (http://www.specialchild.com/ index.html), Family Village (http://www.familyvillage.wisc. edu/index.htmlx), Our Kids (http://www.our-kids.org/), and SchwabLearning.org (http://www.schwablearning.org/index. asp) continue to be developed to further expand parents' understanding of their child, further enhance their ability to advocate, and generally expand knowledge of what interventions can best serve the needs of their child.

\section{CONCLUSION}

For teachers, parents, and students with disabilities, the Internet and the WWW offer tremendous opportunities to engage teachers and parents and positively impact schoolrelated performance of students with disabilities.
For example:

- Parents can monitor their child's class status from home and on their own time.

- Parents can be involved in and updated about activities going on in class.

- There need not be any more end-of-year surprises. (How did my child get that grade?)

- Ongoing access is more efficient than waiting for report card.

- Communication with the teacher is increased.

- Parents do not have to wonder if their child is doing his or her required work.

- Parents can see pictures of in-class projects and activities.

Because access to and use of the Internet and the WWW go beyond the confines of students with disabilities, the potential application to the field of education, it might be argued, is limitless. The challenge for teachers and parents is to continue to examine ways to best integrate online resources for the educational and overall developmental benefit of the student with a disability.

The possibilities of online instructional applications are significant. Further enhancing the connections between teachers and parents and teachers and students is an initial way to illustrate how the technology can be used to extend learning experiences and engagement for students with disabilities. Furthermore, this is just the beginning of the possibilities that exist for students with disabilities as the online environment continues to expand and increase its accessibility to all users. As educators, we should embrace this medium and seek to further explore how it can be used by teachers, parents, and individuals with disabilities.

\section{WEB SITE REFERENCES}

Web Content Accessibility Guidelines (http://www.w3.org/WAI/ wcag-curric/)

Web Content Accessibility Guidelines for the State of Kansas Implementation Guidance Version 1.0 (http://da.state.ks.us/itec/WASGuidance102600.htm)

Bobby (bobby.watchfire.com)

U.S. Federal Government's Section 508 Guidelines (http://www.section508. gov/).

http://www.teach-nology.com/teachers/lesson_plans/ special_ed/).

The Power of 2 (http://powerof2.org)

MCREL (http://www.mcrel.org)

Eisenhower National Clearinghouse (http://www. enc.org/)

Ask ERIC (http://www.askeric.org/Virtual/Lessons/)

DiscoverySchool.com (http://school.discovery.com/ lessonplans/) 
Teachernet (http://teachers.net/lessons/)

The Lesson Plans Page (http://www.lessonplans page.com/)

Teacher's Corner (http://www.teacherscorner.net)

4 Teachers (http://www.4teachers.com)

High Plains Regional Technology Education Consortium's (HPR*TEC) TrackStar (http://trackstar.hprtec.org/).

Thinkquest (http://www.thinkquest.org/)

(http:// coe.jmu.edu/learningtoolbox)

(http://www.iss.stthomas.edu/studyguides)

Study-WEB (http://www.studyweb.com)

BJ Pinchbeck Homework Helper (http://school.discovery. com/homeworkhelp/bjpinchbeck/)

The Homework Spot (http://www.homeworkspot.com/)

Blackboard (http://www.blackboard.com)

Scholastic's Read 180; see http://teacher.scholastic.com/read180/)

Literacy Access Online (http://www.literacyaccessonline.com)

The Intersect Digital Library (http://intersect.uoregon.edu/)

Reading Rockets (http://www.readingrockets.org)

ReadyWeb (http://readyweb.crc.uiuc.edu/)

LDOnline In-Depth-Reading (http://www.ldonline. org/ld_indepth/reading/reading.html.

Electric Teacher's Online Portfolios (http://www.electric teacher.com/onlineportfolio/)

The Electronic Portfolio Development Process (http://tran sition.alaska.edu/www/portfolios/howto/model.html)

The University of Phoenix (www.uophx.edu)

www.kckcc.cc.ks.us/online

AT\&T Network Virtual Academy (www.att.com/learning network/virtualacademy)

Special Education Training on the Web (SETWEB; http://www.coe.uga.edu/setweb/)

The Virginia Consortium for Teacher Preparation in Severe Disabilities (http://kihd.gmu.edu/sdconsortium/)
The Online Academy at the University of Kansas (http://www.onlineacademy.org/)

MathVIDS (Video Instructional Development Source; http://coe.jmu.edu/mathvidsr/)

The Power of 2 (http://powerof2.org)

(http://www.powerof2.org/modules/)

The Staff Development Module

(http://www.elearndesign.org/resources.html)

eLearning Design Lab (http://www.elearn design.org/)

The Assistive Technology Training Project (ATTO) (http://atto.buffalo.edu/)

Using the Computer for Reading (http://atto.buffalo.edu/ registered/ATBasics/Curriculum/Reading/index.php)

Co:Writer 4000; http://atto. buffalo.edu/registered/ Tutorials/cowriter/index.php)

http://www.onlineacademy.org

Cri Du Chat Support Group (http://www.cridchat. u-net.com/)

Down syndrome-Health Issues (http://www.ds-health.com/)

LDOnline (http://www.ldonline.org)

The Council for Exceptional Children's Division for Learning Disabilities TeachingLD (http://www. teachingld.org/)

Scholastic's Teacher Toolkit (http://teacher.scholastic.com/teacher toolkit/)

Down Syndrome Support Group (http://www.nas.com/downsyn/parent.html)

The Father's Network (http://www.fathersnetwork.org/)

Family Village (http://www.familyvillage.wisc.edu)

LDOnline (www.ldonline.org)

Special Child (http://www.specialchild.com/index.html)

Family Village

(http://www.familyvillage.wisc.edu/index.htmlx)

Our Kids (http://www.our-kids.org/)

SchwabLearning.org

(http://www.schwablearning.org/index.asp)

\section{REFERENCES}

Blackhurst, A. E., Lahm, E. A., \& Hales, R. M. (1998). Using an education server software system to deliver special education coursework via the World Wide Web. Journal of Special Education Technology, 13(4), 78-98.

CAST. (1998-1999). Summary of Universal Design Learning Concepts. Available online at http:// www.cast.org

The CEO Forum on Education and Technology. (2001). The CEO forum school technology and readiness report: Key building blocks for student achievement in the 21st century: Washington, DC: Author.

Cognition and Technology Group at Vanderbilt. (1990). Anchored instruction and its relationship to situated cognition. Educational Researcher, 19(6), 2-10.

Collins, B. C., Schuster, J. W., Ludlow, B. L., \& Duff, M. (2002). Planning and delivery of online coursework in special education. Teacher Education and Special Education, 25, 171-186.
Cuban, L. (1986). Teachers and machines. New York: Teachers College Press.

Edyburn, D. (2001). 2000 in review: A synthesis of the special education technology literature. Journal of Special Education Technology, 16(2).

Edyburn, D. (2002), 2001 in review: A synthesis of the special education technology literature. Journal of Special Education Technology, 17(2).

Fine, M. (1994). Chartering urban school reform: Reflections on public high schools in the midst of change. New York, NY: Teachers College Press.

Gardner, J. E., \& Wissick, C. A. (2002). Enhancing thematic units using the World Wide Web: Tools and strategies for students with mild disabilities. Journal of Special Education Technology, 17(1), 27-38.

Higgins, K., Boone, R., \& Williams, D. L. (2000). Technology trends. Intervention in School and Clinic, 36(2), 109-115. 
Joyce, B., \& Showers, B. (2002). Student achievement: Through staff development (3rd ed.). Alexandria, VA: Association for Supervision and Curriculum Development.

Meister, D. G. (2000). Teachers and change: Examining the literature Paper presented at the Annual Meeting of the American Educational Research Association, New Orleans, LA, April 24-28, 2000.

Meyen, Aust, Bui, \& Isaacson (2002). p. 22

Meyen, E. L., Aust, R. J., Bui, Y. N., \& Isaacson, R. (2002). Assessing and monitoring student progress in an e-learning personnel preparation environment. Teacher Education and Special Education, 25, 187-198.

Meyen, E. L., Aust, R. L., Bui, Y. N., Ramp, E., \& Smith, S. J. (2002). The online academy formative evaluation approach to evaluating online instruction. Internet and Higher Education, 5, 89-108.

Office of Technology Assessment. (1995). Teachers and technology making the connection. Washington, DC: United States Congress, Office of Technology Assessment.
Orkwis, R., \& McLane, K. (Fall 1998). A curriculum every student can use: Design principles for student access. ERIC/OSEP Topical Brief. Reston, VA: Council for Exceptional Children.

Spooner, F., Agran, M., Spooner, M., \& Kiefer-O'Donnell, R. (2000). Preparing personnel with expertise in severe disabilities in the electronic age: Innovative programs and technologies. Journal of the Association for Persons with Severe Handicaps, 25(2), 92-103.

Tinker, R. (2001). Future technologies for special learners. Journal of Special Education Technology, 16(4), 31-37.

Walker, T., \& White, C. (2002). Technorealism: The rhetoric and reality of technology in teacher education. Journal of Technology and Teacher Education, 10(1), 63-74.

Wissick, C. A., \& Gardner, J. E. (2002). Multimedia or Not to Multimedia? Teaching Exceptional Children, 32(4), 34-43.

Zirkle, C. (2002). Using the Internet to enhance teacher education. Techniques: Connecting Education and Careers, 77(5), 24-25. 


\title{
$N E W$
}

\section{CHALLENGING ORTHODOXY IN SPECIAL EDUCATION Dissenting Voices}

\author{
Deborah J. Gallagher, University of Northern Iowa \\ Lous Heshusius, York University \\ Richard P. Iano, Temple University (Emeritus) \\ Thomas M. Skrtic, University of Kansas
}

This new book discusses some of the core philosophical concepts in special education and provides an in-depth look at future possibilities. Will the field function much as it does today or make coherent changes? How will the heated debates about full inclusion, labeling, and definitions of disabilities play out? How will the research on instructional practices and teacher preparation generate change? This text will be of considerable interest to professionals and students in special education, disability studies, curriculum, educational administration, and policy studies.

The authors bring together the latest thinking in the philosophy of science, sociology, disability studies, and disciplines outside of special education. The book blends engaging new ideas from experts in the field to understand the present and shape the future of special education.

0304 / paperback / 388 pages / ISBN 0-89108-301-4 / \$54.00

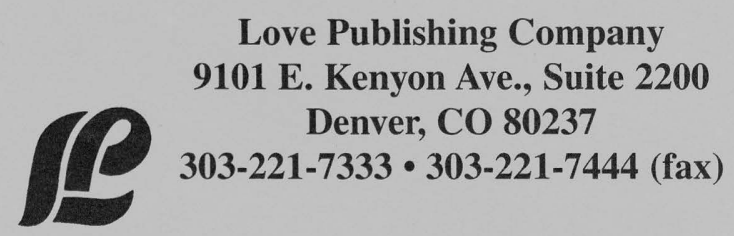

